Published in final edited form as:

Ann Epidemiol. 2011 October ; 21(10): 719-726. doi:10.1016/j.annepidem.2011.04.007.

\title{
All-cause and cause-specific mortality among Black and White North Carolina state prisoners, 1995-2005
}

\author{
David L. Rosen, MD, PhD, \\ The University of North Carolina at Chapel Hill Cecil G. Sheps Center for Health Services \\ Research
}

David A. Wohl, MD, and

The University of North Carolina at Chapel Hill Department of Medicine, Division of Infectious

Diseases

Victor J. Schoenbach, PhD

The University of North Carolina at Chapel Hill Gillings School of Global Public Health

\begin{abstract}
Purpose-We compared mortality rates among state prisoners and other state residents to identify prisoners' healthcare needs

Methods-We linked North Carolina prison records with state death records for 1995-2005 to estimate all-cause and cause-specific death rates among Black and White male prisoners aged 20-79 years, and used standardized mortality ratios (SMRs) to compare these observed deaths with the expected number based on death rates among state residents

Results-The all-cause SMR of Black prisoners was 0.52 (95\%CI: 0.48 0.57), with fewer deaths than expected from accidents, homicides, cardiovascular disease and cancer. The all-cause SMR of White prisoners was 1.12 (95\%CI: 1.01, 1.25) with fewer deaths than expected for accidents, but more deaths than expected from viral hepatitis, liver disease, cancer, chronic lower respiratory disease, and HIV.
\end{abstract}

Conclusions-Mortality of Black prisoners was lower than that of Black state residents for both traumatic and chronic causes of death. Mortality of White prisoners was lower than that of White state residents for accidents, but higher for several chronic causes of death. Future studies should investigate the effect of prisoners' pre-incarceration and in-prison morbidity, the prison environment, and prison healthcare on prisoners' patterns of mortality.

\section{Keywords}

Mortality; Prisoners; Minority Health

(C) 2011 Elsevier Inc. All rights reserved.

Correspondence to: David L. Rosen.

Publisher's Disclaimer: This is a PDF file of an unedited manuscript that has been accepted for publication. As a service to our customers we are providing this early version of the manuscript. The manuscript will undergo copyediting, typesetting, and review of the resulting proof before it is published in its final citable form. Please note that during the production process errors may be discovered which could affect the content, and all legal disclaimers that apply to the journal pertain. 


\section{INTRODUCTION}

The US has the highest incarceration rate in the world ${ }^{1}$ with an estimated 1 in 100 adults in prison or jail on any given day. ${ }^{2}$ One consequence of this mass incarceration is that prisons have become an important source of healthcare for a portion of America's poor.

Providing healthcare in prison presents many challenges. Compared to the general population, prison populations have high rates of morbidity, particularly from infectious diseases, mental health conditions, and substance use. ${ }^{3-5}$ And with the aging of the prison population, prison systems are increasingly confronted with providing care for other chronic diseases. ${ }^{6,7}$ While in principle, prisoners' right to healthcare has been confirmed in the judicial system, ${ }^{8}$ in practice the provision of healthcare may be constrained by overcrowding, competing financial needs, and lack of personnel. ${ }^{9}, 10$

Beyond the provision of healthcare, prisons may influence inmates' health by providing food and shelter as well as opportunities for exercise and health education. For some inmates, prisons also provide a refuge from the substance use and violence endemic in their communities; for others, these threats persist—and in some instances are heightened—in prison. ${ }^{11-13}$

These three factors—baseline morbidity, access to care, and the environment—play important roles in influencing prisoners' health and their mortality. Conversely, mortality rates can inform us of the confluent effect of these factors.

Although several studies have examined prisoner mortality, ${ }^{14-19}$ few have been conducted in the US during the past twenty years. ${ }^{20-22}$ Arguably, the most comprehensive of these more recent studies was a report by the US Bureau of Justice Statistics (BJS), which assessed all deaths of state prisoners, aged 15-64 years, for the years 2001-2004. Similar to older studies, this report found that prisoners had lower death rates than in the general population. But this study was remarkable in that it documented wide disparities in mortality by race. The crude mortality rate for Black prisoners was $57 \%$ less than that of Blacks in the general population (206 vs. 484 per 100,000), while the crude mortality rate of White prisoners was $10 \%$ greater than Whites in the general population (343 vs. 312 per $100,000) .^{20}$

Further refining estimates of mortality by race, Patterson recently published race stratified age-specific mortality rates among US male prisoners for the years1985 to 1998. She found that mortality rates for both Black and White males were each similar to that of nonincarcerated White males. ${ }^{22}$ While the analysis did not include data describing prisoners' cause of death, by excluding traumatic deaths from the comparator (i.e. general) population, Patterson demonstrated that the decrease in mortality among Black prisoners was not entirely due to the environmental protections of prison. Another recent study, which assessed mortality among Georgia state prisoners, found that imprisoned Black men had lower mortality rates than Black men in the general population, although this effect may have been largely an artifact of the state's compassionate release policy. ${ }^{21}$

In this study we use data from a single state to build on the previous examinations of prisoner mortality by race, comparing all-cause and cause-specific mortality among prisoners with that of the general population. Quantification of mortality rates provides a useful albeit blunt barometer to assess prisoners' health and healthcare needs. 


\section{METHODS}

\section{Data sources and linkage}

For the study years 1995 to 2005, we obtained electronic imprisonment records from the North Carolina Department of Correction (NC DOC) and electronic state death records from the North Carolina State Center for Health Statistics. Both sets of records included first and last name, race, sex, date of birth, and last 4 digits of the social security number. In addition, death records included cause and date of death, and imprisonment records included a field indicating whether the inmate died during incarceration. Imprisonment records did not indicate cause of death except for those prisoners who were executed.

To determine prisoners' cause of death, we matched and linked imprisonment and death records based on the personal identifiers common to both databases; matching was conducted using Link Plus software which allows for probabilistic matching of records. ${ }^{23}$

We excluded the thirty three deaths by execution. We also excluded prisoners aged 80 years or older, women, and male prisoners who were neither White nor Black because these groups were too small to calculate race- and age-stratified mortality estimates with adequate precision. Ninety-five percent of records among White and Black male decedent prisoners (797/841) were matched and linked to a state death record. Sixty percent (26/44) of unlinked records were among Blacks.

\section{Cause of death coding}

In state death records, cause of death was coded using the International Classification of Diseases, Ninth Revision, Clinical Modification (ICD-9-CM), for years 1995 to 1998 and the International Statistical Classification of Diseases and Related Health Problems, Tenth Revision (ICD-10), for years 1999 to 2005. The ICD codes were grouped into causes according to the National Center for Health Statistics (NCHS) List of Selected Causes of Death. ${ }^{24}$ Because the NCHS list does not include a mental health category, we constructed this category based on coding for the mental health chapters in the ICD-9-CM and ICD-10. Results are presented for all-causes of death as well as by 11 mutually exclusive categories of death, and 14 substituent causes. We also created a category for alcohol- and druginduced deaths which aggregates deaths from all ICD codes in which alcohol or drug use is explicitly described as the cause (Appendix Table 1).

Prison and state census data-As with other studies of prisoner mortality, ${ }^{20,} 22$ denominator data used to determine death rates among prisoners consisted of age- and racespecific person-years derived with the assumption that the counts of prisoners incarcerated on June $30^{\text {th }}$ of each year during the study period approximated the average number of inmates during the year. We obtained these data by querying the NC DOC website (accessed December 12, 2009).

Denominator data for determining death rates among residents were obtained by querying the CDC's Wide-Ranging OnLine Data for Epidemiological Research Web site, which provides stratum-specific decennial census counts and annual intercensal estimates (accessed December 14, 2009). ${ }^{25,} 26$

\section{Analyses of all-cause and cause-specific mortality}

To compare mortality across imprisonment status, we first estimated crude all-cause mortality rates separately for male prisoners and for other male residents, stratifying by race (Black or White). We used direct standardization (with ages divided into 10-year groups from 20-29 to 70-79) to adjust our mortality estimates for differences in age-composition 
across each population. Age-standardized estimates were weighted using the 2000 US standard population, and CIs and statistical testing accounted for the stratum-specific weights of the standard population. ${ }^{27}$

We examined cause-specific mortality to determine which causes of death contributed to mortality differences between male prisoners and other male state residents. However, for some causes the low number of prisoner deaths resulted in inadequate precision to make comparisons using standardized mortality rates, Accordingly, we used race-stratified standardized mortality ratios (SMRs), to contrast mortality between prisoners and residents. SMRs were estimated as the ratio of observed prisoner deaths divided by expected prisoner deaths. The expected number of prisoner deaths was estimated by multiplying the racespecific death rate for each age stratum of the state resident population by the race-specific number of person-years within each corresponding age-stratum of the prison population and summing the results across all age-strata. We also calculated the difference between observed and expected deaths for each cause.

Approximate 95\% CIs for SMRs were calculated when the observed number of deaths per group was 100 or greater; ${ }^{28}$ for fewer observed deaths, we calculated exact confidence intervals. ${ }^{29}$.All analyses were conducted using SAS version 9.2 (SAS Institute, Cary, NC); SMRs and $95 \%$ CIs were calculated with our own SAS macro.

This study was approved by the Internal Review Board at the University of North Carolina.

\section{RESULTS}

From January 1, 1995 to December 31, 2005, 120,959 unique prisoners aged 20 to 79 years were incarcerated in the NC prison system at least once. Eighty-seven percent $(105,237 / 120,959)$ of these prisoners were male, and of the male prisoners $94 \%$ $(98,870 / 105,237)$ were classified as either White or Black. Of these 98,870 prisoners, $61 \%$ $(60,037)$ were Black, and the median age at admission was 32 years $\left(25^{\text {th }}-75^{\text {th }}\right.$ percentile inter-quartile limits [IQL]: 24-40). Forty-eight percent of adult Black and White male prisoners had a history of multiple imprisonments in the NC DOC, and the median number of lifetime months imprisoned was 13.8 (IQR: 5.4- 38.9) with a total of 302,695 contributed person years at risk. Death during incarceration occurred among less than one percent of Black and White male prisoners $(841 / 98,870)$.

Across age groups and the age-adjusted estimate, death rates among Black and White male prisoners were not statistically different ( $p>0.05$ ) with estimates among Black prisoners generally lower than those of White prisoners (Figure 1, Appendix Table 2). In contrast, Black male residents had higher death rates than White male residents across all age-groups and the age-adjusted estimate $(\mathrm{p}<0.05)$. Comparing mortality rates within race, Black prisoners had lower death rates than Black residents across all age groups while White prisoners had lower death rates than White residents for the youngest age group, but higher death rates for ages 50-79 years.

Among both male prisoners and male residents, the most frequent causes of death were cardiovascular disease and cancer (Table 1). However, infections caused nearly $20 \%$ of deaths among prisoners, but only about 5\% among residents. SMRs among male prisoners differed substantially by race (Table 2). Black prisoners experienced about half the expected number of all-cause deaths (SMR 0.52, 95\%CI: 0.48, 0.57). For several causes, the number of deaths among Blacks was $80 \%$ less than the expected number (i.e. SMRs $<0.2$ ). These causes included alcohol or drugs, diabetes, chronic lower respiratory disease, mental and behavioral disorders, and accidents. There were at least $60 \%$ fewer than expected homicide and suicide deaths, and $36 \%$ and $31 \%$, respectively, fewer than expected deaths from 
cardiovascular disease and cancer. For lung or bronchial cancer, liver cancer, liver disease, and HIV, SMRs included the null. The only cause for which Black prisoners experience an excess number of deaths was viral hepatitis (SMR 3.21, 95\%CI: 1.66, 5.61) (Table 2).

In contrast, among White male prisoners there was an excess number of expected deaths (SMR 1.12, 95\%CI: 1.01, 1.25) for all-cause-mortality (Table 2). However, in a sensitivity analysis which excluded the 18 Whites with a prison record indicating death but no matching state death record, the SMR included the null (Appendix Table 3). By cause, White prisoners experienced the greatest relative excess of deaths for viral hepatitis (SMR 7.18, 95\%CI: 3.83, 12.28) and liver cancer (SMR 5.13, 95\%CI: 2.46, 9.44). Cancer and infections accounted for the greatest absolute excess in deaths, 37 and 21, respectively. There were also excess numbers of deaths from non-alcoholic liver disease and chronic lower respiratory disease while SMR CIs for cardiovascular disease, homicide, suicide, and alcohol/drugs all included the null. Among White prisoners, the greatest absolute difference between observed and expected deaths was for accidental causes, in which the number of deaths observed was 45 fewer than the expected.

\section{DISCUSSION}

In this study, we compared the mortality experience of prisoners with that of the general population and examined how mortality differed across these populations by cause of death and race.

We found that the number of deaths among Black male prisoners was $48 \%$ less than the expected . In contrast, the number of deaths among White male prisoners was only modestly higher than expected, and in a sensitivity analysis this excess was not statistically significant. Our findings echoed those of the Patterson analysis ${ }^{22}$ in that the agestandardized mortality rates for Black and White male prisoners were similar to White residents. These results are in stark contrast to mortality rates in the general populationboth in the US and in NC-in which mortality is about $40 \%$ higher among Blacks than Whites. ${ }^{30}$ These findings suggest that incarceration may play a role in equalizing the mortality experience across race.

There are several possible mechanisms by which incarceration may be protective against or contribute to mortality. Relatively rigid provision of food, shelter, security, and medical and ancillary services may all affect mortality in prison. Similarly, environmental controls in prison may foster a unique set of illicit and unhealthy behaviors. Equivalent exposure to prison resources and environmental elements may contribute to similar mortality rates across race.

Among older prisoners, pre-existing morbidity prior to incarceration undoubtedly plays an important role in determining mortality patterns. While morbidity data were not available to us, a few large studies suggest that the prevalence of some chronic conditions among Black prisoners may be less those of White prisoners ${ }^{31}$ and less than those of Blacks in the general population 31,32 With about $16 \%$ of Black males, but only $2 \%$ of White males, imprisoned during their lifetime, ${ }^{33}$ imprisonment among White men may be a stronger marker for disenfranchisement than for Black men. One consequence may be that White men who are imprisoned may be less healthy than White men who are not; this difference is probably less pronounced for Black men.

Examining cause-specific mortality among Black prisoners, we found that they had fewer than expected deaths from most chronic medical conditions, including the two most common causes of death, cancer and cardiovascular disease. Although SMRs for these causes demonstrate a moderate protective effect (i.e. SMR 0.6) they represent large 
absolute differences between the number of expected and actual deaths. Causes with large absolute differences drive the all-cause mortality patterns and suggest conditions in which interventions may have the greatest public health impact.

It is possible that lower than expected levels of mortality from chronic conditions is the result of a "healthy worker effect." That is, some individuals are not healthy enough to engage in crime, and as a result, prisoners (and ex-prisoners) tend to be healthier than the general population. In a study of English and Welsh prisoners, Fazel and Benning imply that a healthy worker effect is inconsistent with Fazel's previous study showing high rates of morbidity and poor prison healthcare. ${ }^{14}$ Other investigators of prison mortality studies simply concluded that a healthy worker effect was inconsistent with their results. ${ }^{15,21}$ Nonetheless, without both morbidity and mortality data, we cannot rule out the possibilityin these studies and in our own - that some groups of prisoners are healthier than nonprisoners.

Among Black male prisoners, causes of death with a large relative and absolute difference in the number of expected and actual deaths included accidents, homicides, and alcohol and drugs. Given the underlying mechanisms of these types of deaths, it's likely that their prevention was largely due to the environmental controls in prison. Since these causes are among the leading causes of death among young men in the community, it follows that the relatively low number of prisoner deaths from these causes helped to drive down the allcause mortality rates among the youngest age group of both Black and White prisoners.

Among Black male prisoners, the only cause of death with a statistically significant excess of deaths was viral hepatitis; indeed, the SMR for viral hepatitis was the highest among all causes for both Black and White male prisoners, although it accounted for only 3\% (25/797) of all deaths in our population, a proportion similar to that found among Texas prisoners. ${ }^{34}$ Although the high prevalence of hepatitis among prisoners is well known, to our knowledge treatment is not widespread despite favorable cost-effectiveness analyses. ${ }^{35}$

In addition to hepatitis, White prisoners had greater than expected numbers of deaths from non-alcoholic liver disease, cancer (including liver and lung), chronic lower respiratory disease, and HIV; the SMR for cardiovascular disease was modestly elevated but its confidence interval included the null. As we suggested above, high rates of mortality from chronic diseases among Whites may be a reflection of high rates of morbidity among the incoming population; sub-optimal access to or quality of healthcare while in prison is another explanation which merits future study.

Our analyses have some limitations. First, 5\% of records among deceased prisoners could not be linked to state death records. Exclusion of these unlinked prison records from our analyses of cause-specific deaths artificially lowered some of our SMRs. While SMRs were also artificially low because of the compassionate release of dying prisoners, we demonstrated in sensitivity analyses that this effect was negligible. Another limitation is that the small number of deaths among women and prisoners who were neither White nor Black precluded their inclusion in our analysis. Use of death records has several well documented limitations including differential reliability and validity by cause. ${ }^{36}$ As with other studies examining prisoner mortality, the denominators for our death rates were derived from annual one-day censuses of prisoners. While the one-day census underestimates the unique number of prisoners who flow through the prison system annually, it does provide a reasonable estimate of prisoners' person-time at risk. Our estimates of resident deaths constituted all deaths in the population regardless of imprisonment status. Given the relatively high rates of incarceration among Black men, this assumption biased SMR estimates towards the null for 
Blacks more than for Whites. Finally, our findings may not be generalizable to other state prison systems.

Mortality among prisoners may be affected by prisoners' pre-incarceration morbidity, the protective environment of prison, and in addition to other basic resources, the availability of prison healthcare. With Black and White prisoners experiencing far fewer than the number of expected deaths from traumatic causes, this study provides further evidence that prison is protective against these causes. Indeed, of all the factors influencing prisoners' mortality, the protective effect of the prison environment appears to have the greatest absolute impact on our findings. Our findings that Black prisoners experienced fewer chronic disease deaths than expected, but White prisoners experienced more cannot be explained with our data. Nevertheless, these findings provide a blunt assessment of prisoners' general health and they represent a primary step in assessing healthcare need. Future studies should be designed to disentangle the effects of morbidity and prison healthcare on chronic disease mortality to further elucidate the healthcare needs of prisoners during their incarceration and following their release.

\section{Acknowledgments}

None

Financial Support: Dr. Rosen is a postdoctoral fellow at The University of North Carolina. He receives financial support from the Agency for Healthcare Research and Quality Postdoctoral Fellowship (T32 HS019442). Dr. Wohl is an employee of the Division of Infectious Diseases at The University of North Carolina. He receives direct funding from the National Institutes of Health. The division receives research grants from Merck \& Co., Gilead, and GSK. Dr. Schoenbach is an employee of the Department of Epidemiology at The University of North Carolina. He receives direct funding from National Institutes of Health.

\section{Abbreviations and Acronyms}

$\begin{array}{ll}\text { BJS } & \text { Bureau of Justice Statistics } \\ \text { CDC } & \text { Centers for Disease Control and Prevention } \\ \text { CI } & \text { Confidence Interval } \\ \text { ICD } & \text { International Classification of Diseases } \\ \text { IQL } & \text { Inter-Quartile Limits } \\ \text { NCHS } & \text { National Center for Health Statistics } \\ \text { NC } & \text { North Carolina } \\ \text { NC DOC } & \text { North Carolina Department of Correction } \\ \text { SMR } & \text { Standardized Mortality Ratio } \\ \text { SSN } & \text { Social Security Number } \\ \text { US } & \text { United States } \\ \text { vs. } & \text { Versus }\end{array}$

\section{REFERENCES}

1. Walmsley, R. [March 21, 2010] World Prison Population List, Eighth Edition. Available at http://www.kcl.ac.uk/depsta/law/research/icps/downloads/wppl-8th_41.pdf.

2. [April 5, 2008] The Pew Center on the States. One in 100: Behind Bards in America 2008. Available at http://www.pewcenteronthestates.org. 
3. The Health Status of Soon-to-be-Released Inmates, A Report to Congress, Volume 1. National Commission on Correctional Health Care; Chicago: March. 2002

4. Mumola, CJ. Substance Abuse and Treatment, State and Federal Prisoners, 1997. US Department of Justice, Bureau of Justice Statistics; Washington, DC: January. 1999 NCJ 172871

5. James, DJ.; Glaze, LE. Mental Health Problems of Prison and Jail Inmates. US Department of Justice, Bureau of Justice Statistics; Washington, DC: September. 2006 NCJ 213600

6. Mitka M. Aging prisoners stressing health care system. JAMA. Jul 28; 2004 292(4):423-424. [PubMed: 15280325]

7. Williams BA, McGuire J, Lindsay RG, et al. Coming Home: Health Status and Homelessness Risk of Older Pre-release Prisoners. J Gen Intern Med. Jun 8.2010

8. Estelle vs. Gamble. Vol U.S. 97: U.S. Supreme Court. 1976. p. 429

9. Moore, S. [June 10, 2010] California Prisons Must Cut Inmate Population.; The New York Times. August 4. 2009 p. A1 at http://www.nytimes.com/2009/2008/2005/us/2005calif.html

10. MacReady N. Cruel and unusual. Lancet. Feb 28; 2009 373(9665):708-709. [PubMed: 19263584]

11. Sung HE. Prevalence and risk factors of violence-related and accident-related injuries among state prisoners. J Correct Health Care. Jul; 16(3):178-187. [PubMed: 20466703]

12. National Prison Rape Elimination Commission United States. National Prison Rape Elimination Commisssion Report. June. p. 276Available at: http://www.ncjrs.gov/pdffiles1/226680.pdf

13. Gillespie W. A multilevel model of drug abuse inside prison. The Prison Journal. 2005; 85(2):223246.

14. Fazel S, Benning R. Natural deaths in male prisoners: a 20-year mortality study. Eur J Public Health. Aug; 2006 16(4):441-444. [PubMed: 16431869]

15. Clavel F, Benhamou S, Flamant R. Decreased mortality among male prisoners. Lancet. Oct 31; 1987 2(8566):1012-1014. [PubMed: 2889915]

16. Salive ME, Smith GS, Brewer TF. Death in prison: changing mortality patterns among male prisoners in Maryland, 1979-87. Am J Public Health. Dec; 1990 80(12):1479-1480. [PubMed: 2240334]

17. Wobeser WL, Datema J, Bechard B, Ford P. Causes of death among people in custody in Ontario, 1990-1999. Cmaj. Nov 12; 2002 167(10):1109-1113. [PubMed: 12427701]

18. Novick LF, Remmlinger E. A study of 128 deaths in New York City correctional facilities (1971-1976): implications for prisoner health care. Med Care. Sep; 1978 16(9):749-756. [PubMed: 682709]

19. Dalton V. Death and dying in prison in Australia: national overview, 1980-1998. J Law Med Ethics. 1999; 27(3):269-274, 210. Fall. [PubMed: 11067604]

20. Mumola, CJ. Medical Causes of Death in State Prisons, 2001-2004. Bureau of Justice Statistics; Washington, DC: January. 2007 NCJ 216340

21. Spaulding AC, Seals RM, McCallum VA, Perez SD, Brzozowski AK, Steenland NK. Prisoner Survival Inside and Outside of the Institution: Implications for Health-Care Planning. Am J Epidemiol. Jan 14.2011

22. Patterson EJ. Incarcerating death: mortality in U.S. state correctional facilities, 1985-1998. Demography. Aug; 2010 47(3):587-607. [PubMed: 20879679]

23. Winkler, WE. Using the EM Algorithm for Weight Computation in the Fellegi-Sunter Model of Record Linkage. Paper presented at: American Statistical Association 1998 Proceedings of the Section on Survey Research Methods. 1988.

24. National Center for Health Statistics. [October 10, 2006] Documentation for the Public Use Multiple Cause of Death File on Comparability between ICD-9 and ICD-10: A double-coded file based on the 1996 data year multiple cause of death file. ftp://ftp.cdc.gov/pub/Health_Statistics/NCHS/Datasets/Comparability/icd9_icd10/ ICD9_ICD10_comparability_file_documentation.pdf.

25. United States Department of Commerce U.S. Census Bureau Population Division. Census Population 1970-2000 for Public Health Research, CDC WONDER On-line Database, March 2003.. Centers for Disease Control and Prevention (CDC), National Center for Health Statistics (NCHS), Bridged-Race Population Estimates, United States, 1990 - 2003, July 1st resident 
population by state, county, age, sex, race, and Hispanic origin, on CDC WONDER On-line Database, June 2005.

26. United States Department of Health and Human Services (US DHHS). Centers for Disease Control and Prevention (CDC), National Center for Health Statistics (NCHS), Bridged-Race Population

Estimates, United States, July 1st resident population by state, county, age, sex, race, and Hispanic origin, compiled from 2000-2005 (vintage 2005) bridged-race postcensal population estimates, on CDC WONDER On-line Database, April 2007.

27. Lilienfeld, DE.; Stolley, PD. Foundations of Epidemiology. Third ed. Oxford Press; 1994.

28. Rothman, K.; Boice, J, Jr.. Epidemiologic Analysis with a Programmable Calculator. USHEW/ PHS; Washington, D.C.: 1979.

29. Goldblatt, P. Longitudinal Study, Mortality and social organisation. HMSO; London: 1990.

30. Centers for Disease Control and Prevention. [Jul 15, 2010] National Center for Health Statistics. Compressed Mortality File 1999-2006. at http://wonder.cdc.gov/cmficd10.html

31. Binswanger IA, Krueger PM, Steiner JF. Prevalence of chronic medical conditions among jail and prison inmates in the USA compared with the general population. J Epidemiol Community Health. Nov; 2009 63(11):912-919. [PubMed: 19648129]

32. Harzke AJ, Baillargeon JG, Pruitt SL, Pulvino JS, Paar DP, Kelley MF. Prevalence of chronic medical conditions among inmates in the Texas prison system. J Urban Health. May; 2010 87(3): 486-503. [PubMed: 20393884]

33. Bonczar, TP. Prevalence of Imprisonment in the U.S. Population, 1974-2001. US Department of Justice, Bureau of Justice Statistics; Washington, DC: August. 2003 NCJ 197976

34. Harzke AJ, Baillargeon JG, Kelley MF, Diamond PM, Goodman KJ, Paar DP. HCV-related mortality among male prison inmates in Texas, 1994-2003. Ann Epidemiol. Aug; 2009 19(8):582589. [PubMed: 19443239]

35. Tan JA, Joseph TA, Saab S. Treating hepatitis C in the prison population is cost-saving. Hepatology. Nov; 2008 48(5):1387-1395. [PubMed: 18924228]

36. Rosenberg HM. Improving cause-of-death statistics. Am J Public Health. May; 1989 79(5):563564. [PubMed: 2705587] 


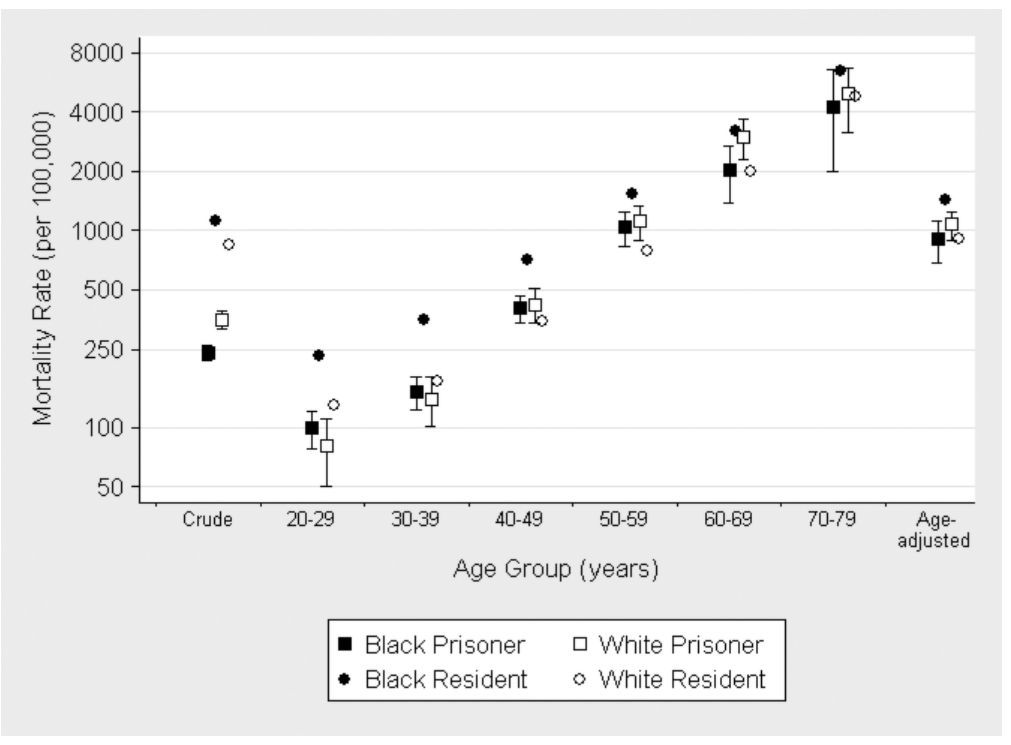

Figure 1.

Race-stratified crude, age stratified, and age adjusted mortality rates among adult male prisoners and other adult male residents, North Carolina, 1995-2005

Mortality rates were calculated for all Black and White adult (aged 20-79 years) males in prison and other adult male state residents across 11 years. Age adjusted estimates were calculated using the US Standard 2000 population. Resident point estimate mortality rates are labeled with circles; prisoner point estimates are labeled with boxes and accompanied by 95\% CIs, presented using lines with caps. Mortality rates are plotted on a log scale. $95 \%$ CI $=$ Ninety-five percent confidence intervals 
Table 1

Cause of death among Black and White adult male NC residents and prisoners, 1995-2005*

\begin{tabular}{|c|c|c|}
\hline & NC residents $(\mathrm{N}=264,792), \%$ & NC Prisoners (N=797), \% \\
\hline \multicolumn{3}{|l|}{ Cardiovascular disease } \\
\hline Total & 33.6 & 27.9 \\
\hline Cerebrovascular disease & 4.8 & 2.8 \\
\hline Ischemic heart disease & 20.3 & 16.8 \\
\hline \multicolumn{3}{|l|}{ Cancer } \\
\hline Total & 27.9 & 24.2 \\
\hline Liver cancer & 0.7 & 2.0 \\
\hline Lung or bronchial cancer & 10.6 & 10.5 \\
\hline \multicolumn{3}{|l|}{ Liver disease and cirrhosis } \\
\hline Total & 1.9 & 2.8 \\
\hline Alcoholic liver disease & 1.1 & 0.8 \\
\hline Causes other than alcohol & 0.8 & 2.0 \\
\hline Diabetes & 3.0 & 0.8 \\
\hline \multicolumn{3}{|l|}{ Infection } \\
\hline Total & 5.3 & 19.7 \\
\hline HIV & 1.6 & 13.8 \\
\hline Viral hepatitis & 0.3 & 3.1 \\
\hline Tuberculosis & 0.0 & 0.0 \\
\hline \multicolumn{3}{|l|}{ Respiratory disease } \\
\hline Total & 6.6 & 2.9 \\
\hline Chronic lower respiratory disease & 5.0 & 2.3 \\
\hline \multicolumn{3}{|l|}{ Mental and behavioral } \\
\hline Total & 1.6 & 0.5 \\
\hline Alcohol & 0.8 & 0.3 \\
\hline Drugs & 0.1 & 0.0 \\
\hline \multicolumn{3}{|l|}{ Accident } \\
\hline Total & 7.1 & 5.3 \\
\hline Motor vehicle accident & 3.6 & 2.8 \\
\hline Drug overdose & 1.0 & 1.4 \\
\hline Homicide & 1.7 & 5.3 \\
\hline Suicide & 2.7 & 3.9 \\
\hline Other & 8.7 & 6.9 \\
\hline Alcohol or drugs ${ }^{\dagger}$ & 3.2 & 3.3 \\
\hline
\end{tabular}




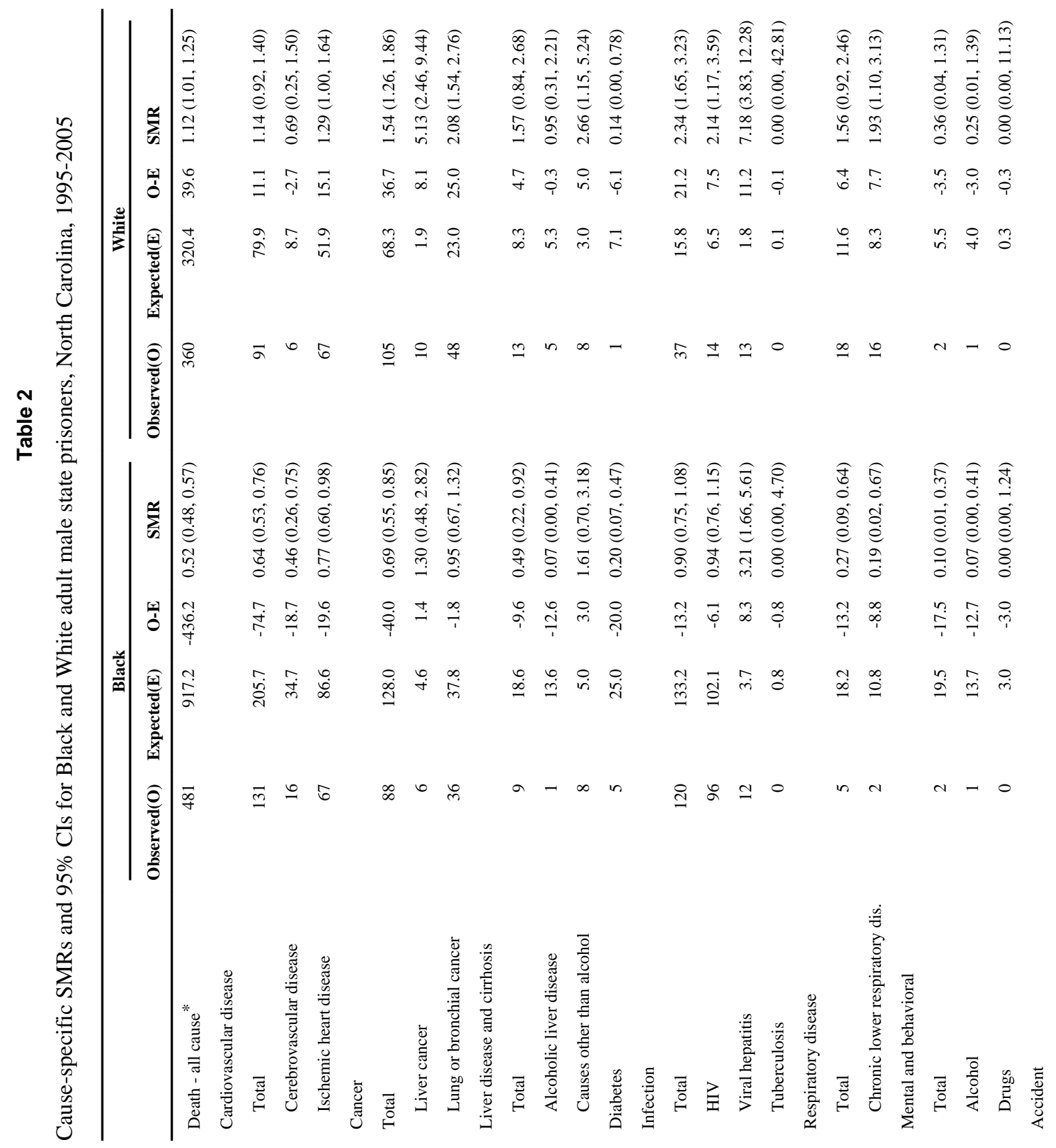

Ann Epidemiol. Author manuscript; available in PMC 2012 October 1. 


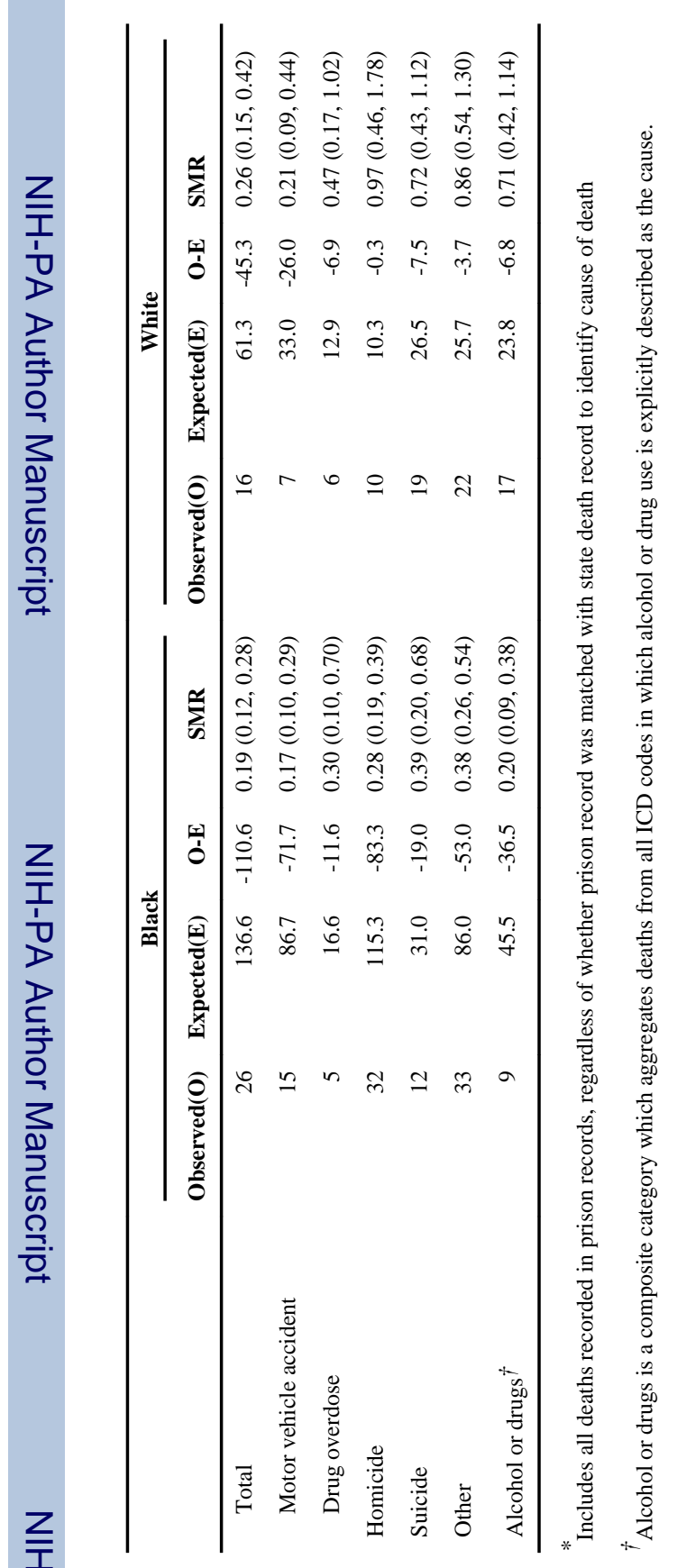

Ann Epidemiol. Author manuscript; available in PMC 2012 October 1. 


\section{Appendix Table 1}

Relationship between study causes and NCHS list*

\begin{tabular}{|c|c|}
\hline & NCHS list number \\
\hline Cardiovascular disease & 053-075 \\
\hline Cerebrovascular disease & 070 \\
\hline Ischemic heart disease & 058-063 \\
\hline Cancer & 020-044 \\
\hline Liver cancer & 024 \\
\hline Lung/bronchial cancer & 027 \\
\hline Liver disease \& cirrhosis & 094,095 \\
\hline Alcoholic liver disease & 094 \\
\hline Other causes & 095 \\
\hline Diabetes & 046 \\
\hline Infection & 001-018, 076-081 \\
\hline HIV & 016 \\
\hline Viral hepatits & 015 \\
\hline Tuberculosis & 004,005 \\
\hline Respiratory disease & 082-089 \\
\hline Chronic lower respiratory & 083-086 \\
\hline Mental \& behavioral $*$ & 290-319; F00-F99 \\
\hline Alcohol ${ }^{*}$ & $303,305.0 ; \mathrm{F} 10$ \\
\hline Drugs* & 304, 305.2-305.9; F11-F16, F19, F55 \\
\hline Accident & $114-123,132-133$ \\
\hline Motor vehicle accident & 114 \\
\hline Drug overdose & 122 \\
\hline Homicide & 128,129 \\
\hline Suicide & 125,126 \\
\hline Other & 045-052, 090-111, 130, 134-135 \\
\hline Alcohol or drugs $*$ & $\begin{array}{l}\text { 303, 304, 305.0, 305.2-305.9, 571.0-571.3, E850-E858, E950.0-E950.5, E962.0, E980.0-E980.5; F10-F16, F19, } \\
\text { F55, K70, K73, K74, X40-X44, X60-X64, X85, Y10-Y14 }\end{array}$ \\
\hline
\end{tabular}

NCHS list available at

ftp://ftp.cdc.gov/pub/Health_Statistics/NCHS/Datasets/Comparability/icd9_icd10/ICD9_ICD10_comparability_file_documentation.pdf

* ICD codes are presented for mental \& behavioral conditions and alcohol- and drug-induced deaths 


\section{Appendix Table 2}

Age-specific and age-standardized mortality rates* among adult Black and White male state prisoners, North Carolina, 1995-2005

\begin{tabular}{ccc}
\hline & NC prisoners & NC residents \\
\hline Black 20-29 years & $99.5(78.1,120.9)$ & $230.4(222.6,238.2)$ \\
$30-39$ & $151.2(122.2,180.2)$ & $354.5(344.7,364.4)$ \\
$40-49$ & $403.1(338.3,467.9)$ & $712.5(698,726.9)$ \\
$50-59$ & $1036.1(832.0,1,240.1)$ & $1535.3(1509,1561.6)$ \\
$60-69$ & $2033.7(1,366.8,2,700.6)$ & $3171.9(3122.6,3221.2)$ \\
$70-79$ & $4248.4(1,988.5,6,508.2)$ & $6461.1(6371.2,6551)$ \\
Age-adjusted ${ }^{\dagger}$ & $899.5(688.1,1,110.9)$ & $1435.5(1424.3,1446.7)$ \\
White 20-29 years & $80.5(50.2,110.9)$ & $130.0(126.8,133.2)$ \\
$30-39$ & $140.1(100.9,179.3)$ & $172.2(168.7,175.8)$ \\
$40-49$ & $421.0(336.9,505.0)$ & $345.4(340.3,350.6)$ \\
$50-59$ & $1113.4(884.7,1,342.2)$ & $786.9(778.1,795.6)$ \\
$60-69$ & $2991.5(2,301.2,3,681.7)$ & $2000.4(1983.5,2017.2)$ \\
$70-79$ & $4912.3(3,138.0,6,686.6)$ & $4802.8(4771,4834.5)$ \\
& $1070.4(894.6,1,246.2)$ & $900.6(896.7,904.5)$ \\
\hline Age-adjusted ${ }^{\dagger}$ & & \\
\hline \multirow{2}{*}{${ }^{\dagger}$ adjuster 100,000 } & &
\end{tabular}

Ann Epidemiol. Author manuscript; available in PMC 2012 October 1. 


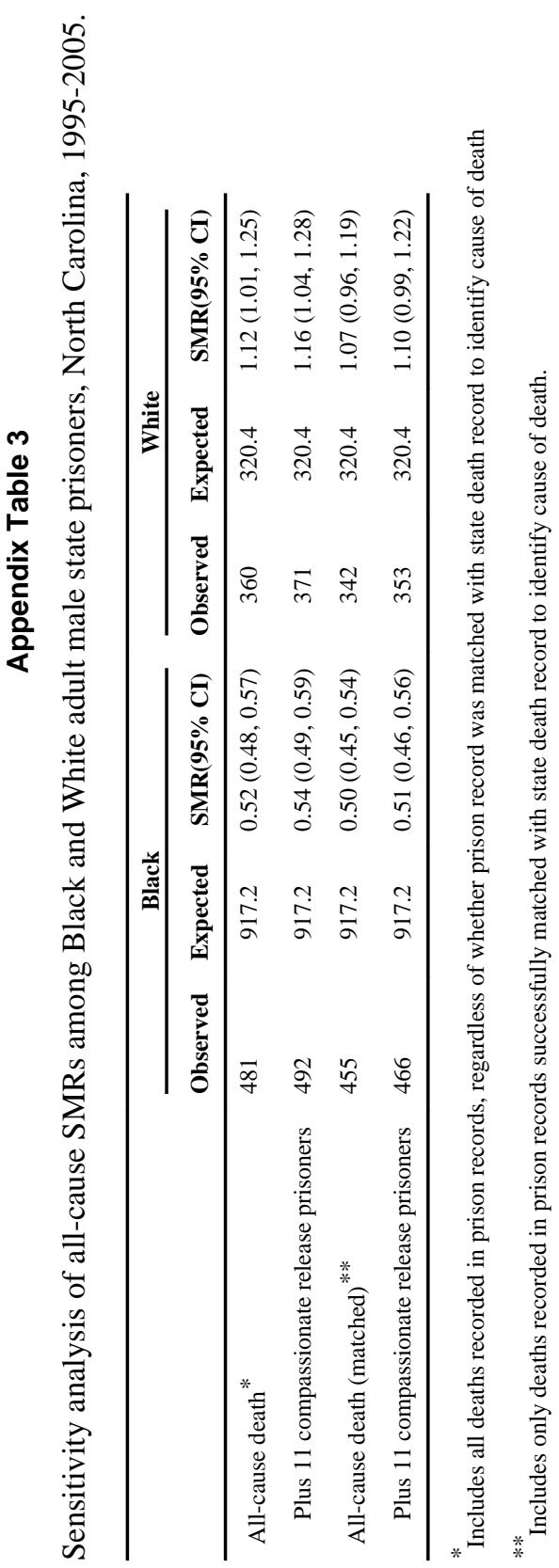

